\title{
Ballistic Efficiency of Hybrid Laminates Based on Aramid and UHMWPE Pre- pregs
}

Irena Beránková (0000-0002-7568-2531), Regina Mikulíková (0000-0002-8252-1883), Jan Křest’an (0000-00017118-8045)

Vojenský výzkumný ústav, s. p., Veslařská 230, 63700 Brno, Czech Republic. E-mail: berankova@vvubrno.cz, mikulikova@vvubrno.cz,krestan@vvubrno.cz

The work is focused on comparison of ballistic efficiency of homogeneous laminates consisting of one type of prepreg based on aramid or UHMWPE and ballistic efficiency of hybrid laminates consisting of combitation of chosen prepregs layered in different order. For preparation of hybrid laminates the two types of aramid prepregs and two types of UHMWPE prepregs were chosen. The laminates were subjected to ballistic testing by fragment simulating projectile FSP G5 and their ballistic efficiency was evaluated by determination of ballistic limit $V_{50}$. For more complex assessment of tested laminates with regard to ballistic efficiency and also their areal weight, the ballistic weight coefficient $K$, which is defined by quotient of $V_{50}$ and areal weight, was determined for each laninate and then compared. Besides the ballistic efficiency the coherence of laminate layers after pressing and after shooting was also observed.

Keywords: Hybrid Laminates, Ballistic Efficiency, Ballistic Limit $\mathrm{V}_{50}$, Coherence

\section{Introduction}

Commercial suppliers of the ballistic laminates usually offer only the homogeneous laminates consisted of one type of fabric and one type of matrix. The laminates are usually produced by pressing of specific prepregs under given conditions. Generally the prepreg could be defined as the fabric coated by the matrix on one or both sides. Huge number of different types of prepregs can be prepared, because many types of fabrics of different material and weave and also many types of various matrixes are available. The ballistic efficiency of final laminate could be influenced by different type of fabric material, weave, matrix and also by combination of various prepregs and order of prepreg layers.

In this work the four types of prepregs was choses Tab. 1 Prepregs used for laminates preparation

\begin{tabular}{|l|l|l|}
\hline Designation & Description & $\begin{array}{l}\text { Thickness after pressing } \\
{[\mathrm{mm}]}\end{array}$ \\
\hline PH & UHMW $\underline{\mathbf{P} E}$ sheet with $\underline{\text { Higher ballistic efficiency }}$ & 0.17 \\
\hline PL & UHMW $\underline{\mathbf{P}}$ Eheet with $\underline{\text { Lower ballistic efficiency }}$ & 0.23 \\
\hline AB & $\underline{\text { Aramid fabric with } \underline{\text { Basket weave }}}$ & 0.41 \\
\hline AP & $\underline{\text { Aramid fabric with } \underline{\mathbf{P}} \text { lain weave }}$ & 0.45 \\
\hline
\end{tabular}

By combination of different types of prepregs the hybrid laminates were prepared. In one hybrid laminate only two types of prepregs were combined. All the hybrid laminates were designed to have a total thicknes of about $8 \mathrm{~mm}$. The two prepreg types in one and combined in the two-part and three-part hybrid laminates. The ballistic efficiency of the prepared laminates was evaluated by the method of the ballistic limit $V_{50}$ determination, which is one of the most common methods of ballistic laminates assessment [1, $2,3,4,5]$.

\section{Methodology}

\subsection{Samples preparation}

Samples of laminates were prepared by pressing of respective number of prepreg layers in laboratory pressing machine under defined pressure and temperature. Samples dimension was approximately $500 \mathrm{x}$ $500 \mathrm{~mm}$. Four types of prepregs were used, see $\boldsymbol{T} \boldsymbol{a} \boldsymbol{b}$. 1. All the prepreg types were coated by matrix only on one side. hybrid laminate were contained in a half-and-half portion. That means the number of layers of one prepreg type was designed to reach the thickness of about 4 $\mathrm{mm}$. The list of hybrid laminates is introduced in $\mathbf{T a b}$. 2. The numbers in designation of samples represent the number of layers of respective prepreg type. 
Tab. 2 Hybrid laminates prepared for testing

\begin{tabular}{|l|l|l|}
\hline Designation & $\begin{array}{l}\text { Thickness } \\
{[\mathrm{mm}]}\end{array}$ & $\begin{array}{l}\text { Areal Weight } \\
{\left[\mathrm{kg} / \mathrm{m}^{2}\right]}\end{array}$ \\
\hline $\mathrm{PL}_{17}-\mathrm{AB}_{10}$ & 8.1 & 7.77 \\
\hline $\mathrm{PH}_{23}-\mathrm{AB}_{10}$ & 7.9 & 7.73 \\
\hline $\mathrm{PL}_{17}-\mathrm{AP}_{9}$ & 7.9 & 7.67 \\
\hline $\mathrm{PL}_{9}-\mathrm{AB}_{10}-\mathrm{PL}_{8}$ & 8.2 & 8.24 \\
\hline $\mathrm{PH}_{12}-\mathrm{AB}_{10}-\mathrm{PH}_{11}$ & 8.5 & 8.76 \\
\hline $\mathrm{PL}_{9}-\mathrm{AP}_{9}-\mathrm{PL}_{8}$ & 8.1 & 8.28 \\
\hline
\end{tabular}

For comparison also the homogeneous laminates containing only one prepreg type were prepared as reference samples. The reference laminates was also designed to have the total thickness of about $8 \mathrm{~mm}$. The list of reference laminates is introduced in $\mathbf{T a} \boldsymbol{b} . \mathbf{3}$.

Tab. 3 Reference homogeneous laminates prepared for testing

\begin{tabular}{|l|l|l|}
\hline Designation & $\begin{array}{l}\text { Thickness } \\
{[\mathrm{mm}]}\end{array}$ & $\begin{array}{l}\text { Areal Weight } \\
{\left[\mathrm{kg} / \mathrm{m}^{2}\right]}\end{array}$ \\
\hline $\mathrm{PH}_{48}$ & 8.0 & 6.90 \\
\hline $\mathrm{PL}_{35}$ & 8.0 & 6.90 \\
\hline $\mathrm{AB}_{19}$ & 7.8 & 8.10 \\
\hline $\mathrm{AP}_{17}$ & 7.7 & 8.00 \\
\hline
\end{tabular}

\subsection{Experimental testing}

The ballistic efficiency of the laminates samples was evaluated by determination of the ballistic limit $\mathrm{V}_{50}$. The ballistic limit $\mathrm{V}_{50}$ is defined as the striking velocity at which $50 \%$ of the impacts of a projectile will result in complete penetration (perforation) of a given sample on specified attack conditions [6]. The ballistic testing was conducted by fragment simulating projectile FSP G5 without carrier of diameter (5.46 \pm $0.05) \mathrm{mm}$ and weight $(1.1 \pm 0.03) \mathrm{g}$ according to standard STANAG 2920 [7]. The distance of the target from the muzzle was $5 \mathrm{~m}$. The shot pattern is introduced on the Fig. 1.

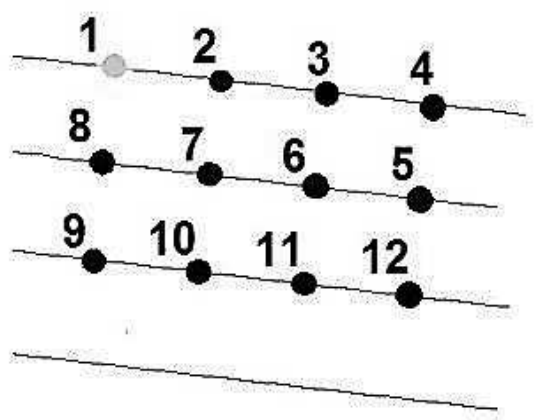

The shot distance from sample edge and the distance between two neighbouring shots was minimally $28 \mathrm{~mm}$ (5 projectile calibres). The ballistic limit $\mathrm{V}_{50}$ was determined from 6 valid shots within velocity range $40 \mathrm{~m} . \mathrm{s}^{-1}$, whereof 3 shots perforated the sample and 3 shots did not perforate the sample [5].

The two-part hybrid laminates, in which the two different types of prepregs create only two parts of thickness $4 \mathrm{~mm}$, were subjected to ballistic testing from both sides. These types of laminates are following: $\mathrm{PL}_{17}-\mathrm{AB}_{10}$ vs $\mathrm{AB}_{10}-\mathrm{PL}_{17}, \mathrm{PH}_{23}-\mathrm{AB}_{10}$ vs $\mathrm{AB}_{10}-\mathrm{PH}_{23}$ and $\mathrm{PL}_{17}-\mathrm{AP}_{9}$ vs $\mathrm{AP}_{9}-\mathrm{PL}_{17}$.

For more complex assessment of tested laminates with regard to ballistic efficiency and also their areal weight, the ballistic weight coefficient $K$, which is defined by quotient of $V_{50}$ and areal weight (1), was determined for each laminate.

$$
K=\frac{V_{50}}{A W}\left[m \cdot s^{-1} / k g \cdot m^{-2}\right],
$$

Where:

$\mathrm{K} \quad$...Ballistic weight coefficient $\left[\mathrm{m} \cdot \mathrm{s}^{-1} / \mathrm{kg} \cdot \mathrm{m}^{-2}\right]$

$\mathrm{V}_{50} \quad \ldots$ Ballistic limit $\left[\mathrm{m}_{\mathrm{s}} \mathrm{s}^{-1}\right]$

AW...Areal weight [kg.m-2]

The higher value of the coefficient $\mathrm{K}$ the better utility properties of the laminate.

\section{Results and discussion}

\subsection{Ballistic efficiency}

Illustrations of the sample of the two-part hybrid laminate after ballistic testing are introduced on Fig. 2 and Fig. 3. The Fig. 2 shows the UHMWPE front side of the hybrid laminate $\mathrm{PL}_{17}-\mathrm{AB}_{10}$ and Fig. 3 shows the aramid back side of the same hybrid laminate.

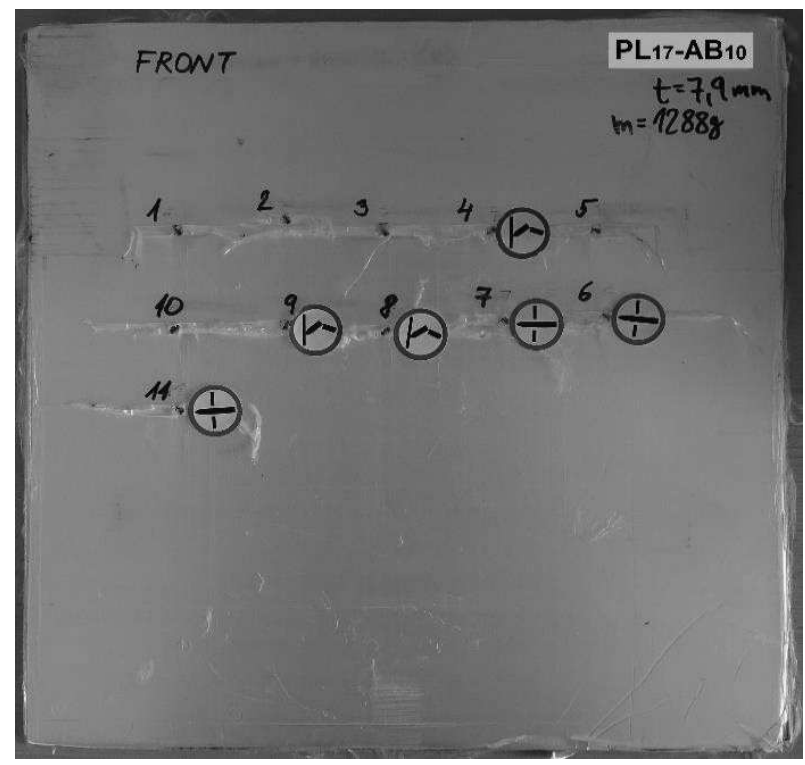

Fig. 2 Front (striking) side of bybrid laminate $P L_{17-} A B_{10}$ after ballistic testing

Fig. 1 Shot pattern 


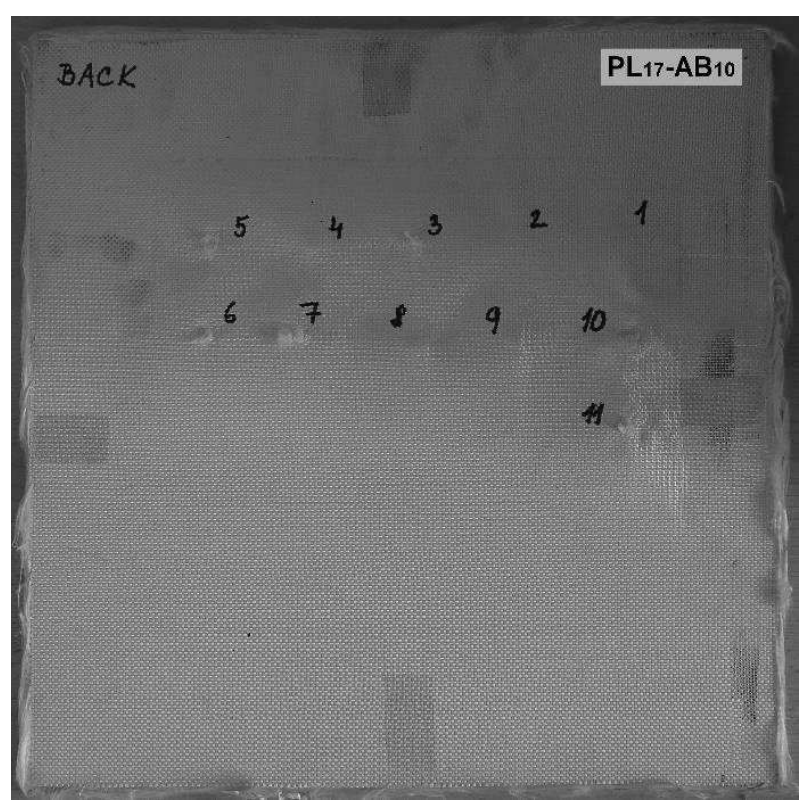

Fig. 3 Back side of bybrid laminate $P L_{17}-A B_{10}$ after ballistic testing

The results of ballistic testing expressed by the ballistic limit $\mathrm{V}_{50}$ and the ballistic weight coefficient $\mathrm{K}$ for hybrid and reference homogeneous laminates are introduced in Tab. 4 and Tab. 5 below.

Data in $\boldsymbol{T a b} . \mathbf{4}$ and $\boldsymbol{T} \boldsymbol{a} \boldsymbol{b} . \boldsymbol{5}$ are intoduced also in form of graphs below, see $\boldsymbol{F i g} . \mathbf{4}$ and $\boldsymbol{F i g} . \boldsymbol{5}$.

The graph on Fig. 4 shows the comparison of the ballistic limit $\mathrm{V}_{50}$ for hybrid and reference laminates. The columns are divided into groups of samples, where the same two prepreg types were used. The margins of each group are represented by the two types of the reference homogeneous laminates relating to the respective group.
Tab. 4 Results of the ballistic limit $V_{50}$ and the ballistic weight coefficient K for bybrid laminates; symbol (r) means "reversed" composition of laminate mentioned in row above

\begin{tabular}{|l|l|l|}
\hline Designation & $\begin{array}{l}\mathrm{V}_{50} \\
{[\mathrm{~m} / \mathrm{s}]}\end{array}$ & $\begin{array}{l}\mathrm{K} \\
{\left[\mathrm{m} . \mathrm{s}^{-1} / \mathrm{kg} \cdot \mathrm{m}^{-2}\right]}\end{array}$ \\
\hline $\mathrm{PL}_{17}-\mathrm{AB}_{10}$ & $\begin{array}{l}722.6 \pm \\
13.4\end{array}$ & 93.0 \\
\hline $\mathrm{AB}_{10}-\mathrm{PL}_{17}(\mathrm{r})$ & $\begin{array}{l}671.4 \pm \\
15.2\end{array}$ & 86.4 \\
\hline $\mathrm{PH}_{23}-\mathrm{AB}_{10}$ & $\begin{array}{l}736.5 \pm \\
19.7\end{array}$ & 95.3 \\
\hline $\mathrm{AB}_{10}-\mathrm{PH}_{23}(\mathrm{r})$ & $\begin{array}{l}694.9 \pm \\
19.4\end{array}$ & 89.9 \\
\hline $\mathrm{PL}_{17}-\mathrm{AP}_{9}$ & $\begin{array}{l}686.0 \pm \\
15.5\end{array}$ & 89.4 \\
\hline $\mathrm{AP}_{9}-\mathrm{PL}_{17}(\mathrm{r})$ & $\begin{array}{l}644.9 \pm \\
18.0\end{array}$ & 84.1 \\
\hline $\mathrm{PL}_{9}-\mathrm{AB}_{10}-\mathrm{PL}_{8}$ & $\begin{array}{l}687.7 \pm \\
15.0\end{array}$ & 83.5 \\
\hline $\mathrm{PH}_{12}-\mathrm{AB}_{10}-\mathrm{PH}_{11}$ & $\begin{array}{l}735.8 \pm \\
18.2\end{array}$ & 84.0 \\
\hline $\mathrm{PL}_{9}-\mathrm{AP}_{9}-\mathrm{PL}_{8}$ & $\begin{array}{l}664.7 \pm \\
17.5\end{array}$ & 80.3 \\
\hline
\end{tabular}

Tab. 5 Results of the ballistic limit $V_{50}$ and the ballistic weight coefficient K for reference homogeneous laminates

\begin{tabular}{|l|l|l|}
\hline Designation & $\begin{array}{l}\mathrm{V}_{50} \\
{[\mathrm{~m} / \mathrm{s}]}\end{array}$ & $\begin{array}{l}\mathrm{K} \\
{\left[\mathrm{m} . \mathrm{s}^{-1} / \mathrm{kg} \cdot \mathrm{m}^{-2}\right]}\end{array}$ \\
\hline $\mathrm{PH}_{48}$ & $741.1 \pm 9.6$ & 107.4 \\
\hline $\mathrm{PL}_{35}$ & $660.6 \pm 7.9$ & 95.7 \\
\hline $\mathrm{AB}_{19}$ & $\begin{array}{l}666.5 \pm \\
10.6\end{array}$ & 82.3 \\
\hline $\mathrm{AP}_{17}$ & $\begin{array}{l}617.1 \pm \\
11.2\end{array}$ & 77.1 \\
\hline
\end{tabular}

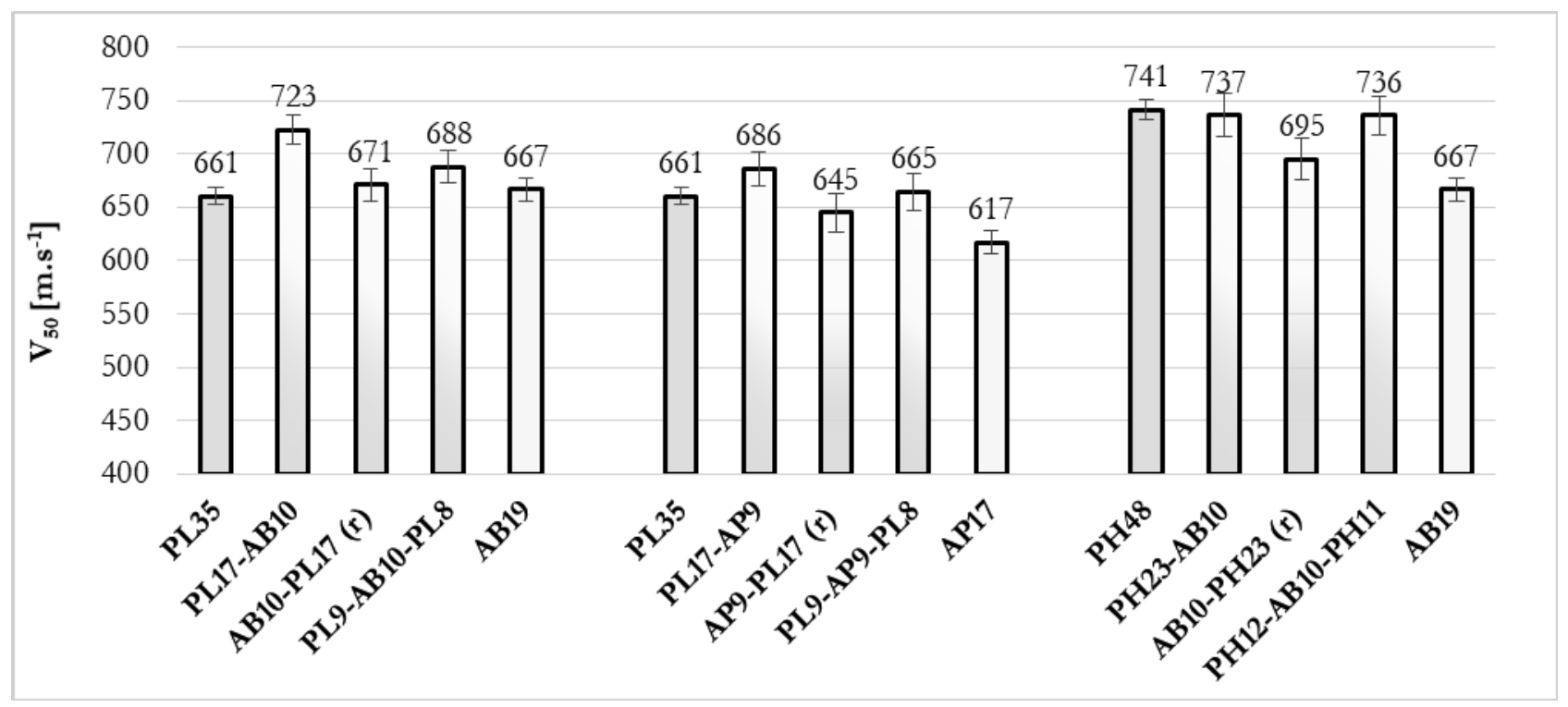

Fig. 4 Comparison of the ballistic limit $V_{50}$ for bybrid and reference laminates; blue columns $=$ reference UHMWPE laminates, yellow columns $=$ reference aramid laminates, blue-yellow columns $=$ bybrid laminates 
According to graph on Fig. 4, which compares the ballistic limit $\mathrm{V}_{50}$ of different laminates of similar thickness of about $8 \mathrm{~mm}$, the ballistic efficiency of homogeneous plain-woven aramid laminate $\left(\mathrm{AP}_{17}\right)$ is lower than of the basket-woven one $\left(\mathrm{AB}_{19}\right)$ and the lower ballistic efficiency of UHMWPE laminate $\mathrm{PL}_{35}$ in comparison with $\mathrm{AH}_{48}$ was veryfied.

The ballistic limit of the homogeneous aramid laminates is similar or lower than of the homogeneous UHMWPE laminates.

The ballistic limit of the hybrid laminates with
UHMWPE front side is always higher than of the reversed ( $r$ ) composition with aramid front side.

The ballistic limit of the hybrid laminates with PL prepreg is higher than of the homogeneous $\mathrm{PL}_{35}$ laminate.

The ballistic limit of the hybrid laminates with $\mathrm{PH}$ prepreg is similar to the homogeneous $\mathrm{PH}_{48}$ laminate.

The graph on Fig. 5 shows the comparison of the ballistic weight coefficient $\mathrm{K}$ for hybrid and reference laminates. The columns are arranged in the same way as on the Fig. 4.

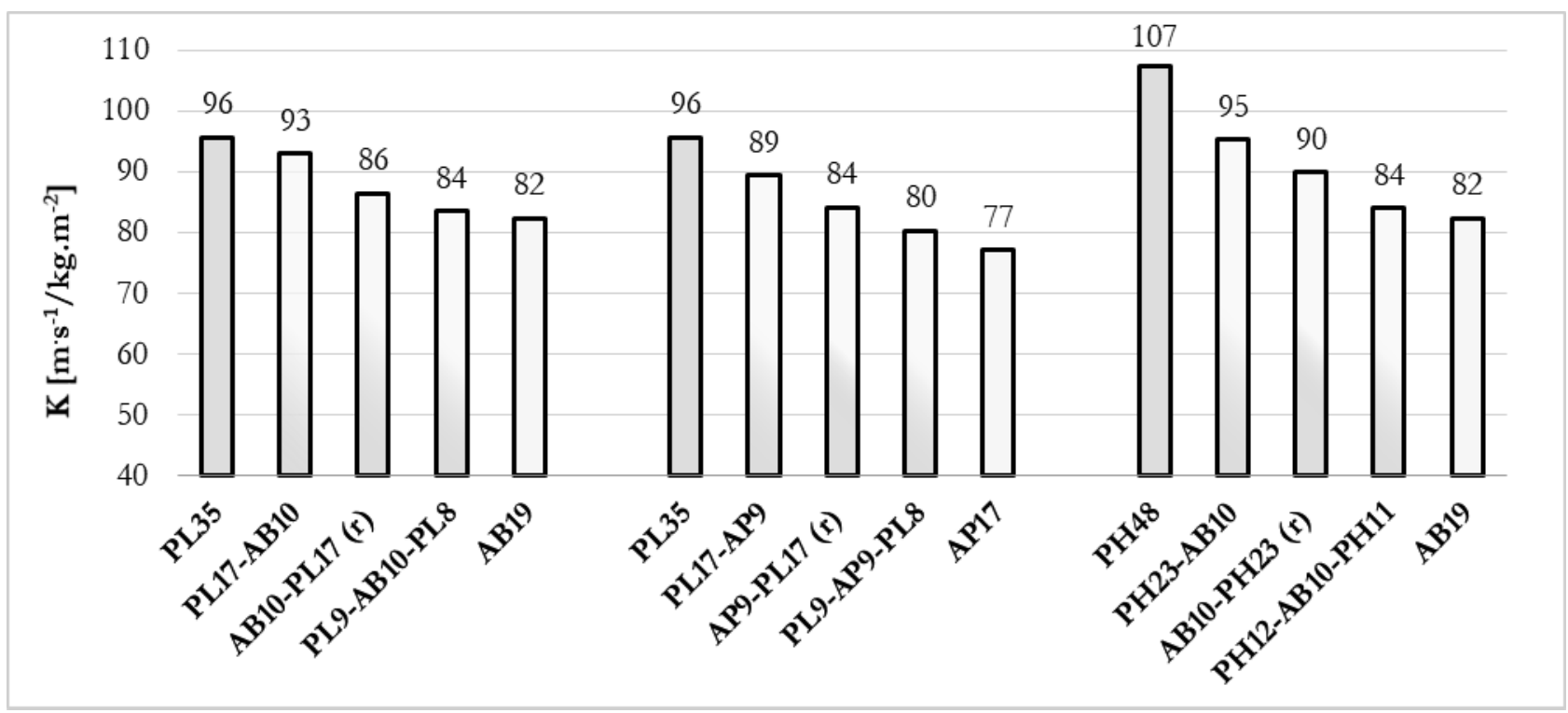

Fig. 5 Comparison of the ballistic weight coefficient $K$ for bybrid and reference laminates; blue columns $=$ reference UHMWPE laminates, yellow columns $=$ reference aramid laminates, blue-yellow columns $=$ bybrid laminates

According to graph on Fig. 5, which compares the ballistic weight coefficient $\mathrm{K}$ considering also the areal weight of the laminates, the ballistic-weight efficiency of homogeneous UHMWPE laminates is always the greatest and of homogeneous aramid laminates is the lowest.

\subsection{Coherence}

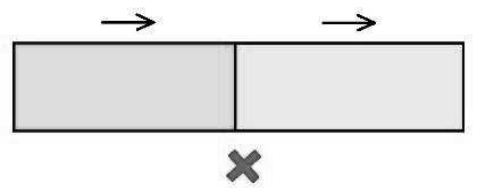

after pressing

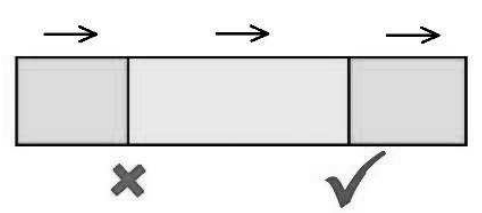

after pressing

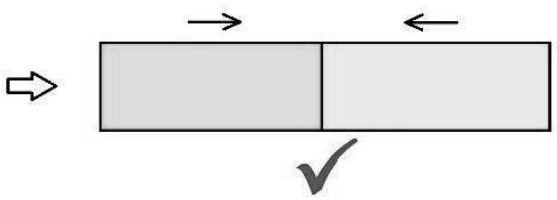

after pressing and ballistic testing

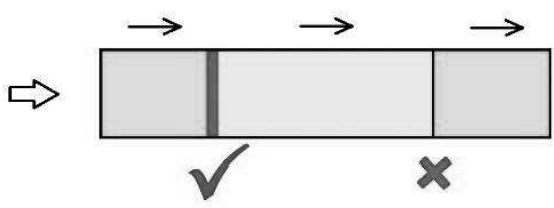

after ballistic testing
Besides the ballistic efficiency the coherence of hybrid laminate layers after pressing and after ballistic testing was observed $[8,9]$. During the hybrid laminates preparation the orientation of one-side coated prepregs had to be considered. On Fig. $\boldsymbol{\sigma}$ the development evolution of the hybrid laminates with regard to UHMWPE/aramid boundary coherence after pressing and after ballistic testing is shown.

Fig. 6 Scheme of UHMWPE/aramid boundary coherence after pressing and after ballistic testing 
If the prepregs in the two-part hybrid laminates (see Fig. 6, schemes at the top) were oriented in the same direction the UHMWPE/aramid boundary did not cohere after laminate pressing. If these prepregs were oriented in the opposite direction (matrixes of two prepregs were oriented to each other) the boundary coherence was good after pressing and also after ballistic testing.

If the prepregs in the three-part hybrid laminates (see Fig. 6, schemes at the bottom) were oriented in the same direction the UHMWPE/aramid boundary did not cohere and the aramid/UHMWPE boundary cohered after laminate pressing.

The UHMWPE/aramid boundary in the threepart hybrid laminates was improved by one layer of film adhesive and pressed again. Both boundaries cohered after pressing, but the aramid/UHMWPE boundary did not cohere after ballistic testing.

If the both boundaries in the three-part hybrid laminates were improved by one layer of film adhesive, all the layers of the hybrid laminate cohered after ballistic testing.

\section{Conclusion}

The ballistic efficiency of the UHMWPE/aramid hybrid laminates consisting of two different prepregs was observed. The two types of hybrid laminates were studied: two-part hybrid laminates and three-part hybrid laminates. For preparation of the hybrid laminates the four different prepregs were used (AP, AB, PL and $\mathrm{PH})$. The ballistic efficiency of the hybrid laminates was evaluated by determination of the ballistic limit $\mathrm{V}_{50}$, which was compared with the ballistic limit of the reference homogeneous laminates consisting of only one type of prepreg. All the laminates were designed to have a total thicknes of about $8 \mathrm{~mm}$.

It was found out that the ballistic limit $\mathrm{V}_{50}$ of the homogeneous AP-aramid laminate was lower than of the homogeneous $\mathrm{AB}$-aramid laminate and the ballistic limit of the homogeneous PL-UHMWPE laminate was lower than of the homogeneous PH-UHMWPE laminate. The ballistic limit of the homogeneous aramid laminates was similar or lower than of the homogeneous UHMWPE laminates.

The ballistic limit of the hybrid laminates with UHMWPE front side was always higher than of the reversed composition with aramid front side.

The ballistic limit of the hybrid laminates with the UHMWPE front side was always higher than of the homogeneous aramid laminates and similar or higher than of the homogeneous UHMWPE laminates.

With regards to results of the ballistic weight coefficient $\mathrm{K}$, which considers also the areal weight of the laminates, the ballistic-weight efficiency of the homogeneous UHMWPE laminates was always the greatest and of homogeneous aramid laminates the lowest.

The coherence of the UHMWPE/aramid boundary in the hybrid laminates after pressing and after ballistic testing was also observed. The two-part hybrid laminates cohered in case, if the different prepregs were oriented in the opposite direction (matrixes of two prepregs were oriented to each other). The threepart hybrid laminates cohered in case, if the both aramid/UHMWPE boundaries were improved by one layer of film adhesive.

\section{Acknowledgement}

The work was supported by the Ministry of Defence of the Czech Republic in connection with platform 907930.

\section{References}

[1] LOGANATHAN, T.M., SULTAN, M.T.H., GOBALAKRISHNAN, M.K., MUTHAIYAH, G. (2018). ResearchGate, pp. 171 - 191. Malaysia.

[2] NAYAK, N., SIVARAMAN, P., BANERJEE, A., MADHU, V., DUTTA, A.L., MISHRA, V.S., CHAKRABORTY, B.C. (2012). ResearchGate, pp.443 - 450. India.

[3] ĆWIK, T.K., IANNUCCI, L., CURTIS, P., POPE, D. (2016). Applied Composite Materials, pp. $717-733$. UK.

[4] PANDYA, K.S., POTHNIS, J.R., RAVIKUMAR, G., NAIK, N.K., (2013). Material Design, p.p. 128 -135. ISSN

[5] NAIK, N.K., DOSHI, A.V., (2008). Composite Structures, p.p. $447-464$.

[6] NATO STANDARD AEP-55 (2014), Vol. 1, Ed. C, NSA, Brussels.

[7] NATO STANDARD AEP-2920 (2015), Ed. 3, NSA, Brussels.

[8] KHORAMISHAD, H., MOUSAVI, M.V., (2019). AIP Conference Proceedings 2144, p.p. 030030-1 - 030030-7.

[9] PHADNIS, V.A., PANDYA, K.S., NAIK, N.K., ROY, A., SILBERSCHMIDT, V.V. (2015). Journal of Physics: Conference Series 628, p.p. $1-8$. 